\title{
Beneficial Effects of Education on Emotional Distress, Self-Management, and Coping in Patients with Inflammatory Bowel Disease: A Prospective Randomized Controlled Study
}

\author{
Anja Berding ${ }^{\mathrm{a}, \mathrm{b}} \quad$ Christine Witte $^{\mathrm{a}}$ Marion Gottschald ${ }^{\mathrm{a}}$ Birgit Kaltz $^{\mathrm{a}}$ \\ Romy Weiland $^{b}$ Christian Gerlich $^{b}$ Andrea Reusch ${ }^{b}$ Wolfgang Kruis ${ }^{c}$ \\ Hermann Faller ${ }^{\text {b }}$ \\ ${ }^{a}$ German Crohn's and Colitis Association (DCCV e.V.), Berlin, ${ }^{b}$ Department of Medical Psychology, Medical \\ Sociology, and Rehabilitation Sciences, University of Würzburg, Würzburg, and 'Department of Internal Medicine, \\ Protestant Hospital Kalk, Cologne, Germany
}

\section{Keywords}

Coping - Inflammatory bowel disease - Patient education .

Quality of life - Self-management · Worries and concerns

\begin{abstract}
Background: Patients with inflammatory bowel disease (IBD) suffer from various physical as well as psychological impairments, and patient education may help improve their well-being. Therefore, we developed a manualized education program for IBD patients addressing medical and psychological issues. This study aimed to evaluate it in a large controlled trial. Methods: A total of 181 IBD outpatients participated in a prospective, randomized, waitlist-controlled trial; assessments were made before as well as 2 weeks and 3 months after intervention. Analysis of covariance was used to assess intervention effects on disease-related worries and concerns (primary outcome), fear of progression, coping with anxiety, health competencies, health-related quality of life (HRQoL), perceived disease activity, symptoms of depression and anxiety, disease-related knowledge, and coping strategies. Participants' satisfaction with the program was also evaluated. Results: At 2 weeks and 3 months after intervention, we found significant large effects of our education program on skill and technique acquisition, knowledge,
\end{abstract}

\section{KARGER}

E-Mail karger@karger.com

www.karger.com/iid and coping with IBD. Moreover, we found significant medium effects on disease-related worries and concerns, fear of progression, coping with anxiety, constructive attitudes and approaches, as well as coping with disease-related negative emotions. The number of coping strategies used was significantly higher at 3 months. We did not find any effects on perceived disease activity, HRQoL, positive and active engagement in life, or symptoms of anxiety and depression. The program was rated very favorably by the attendees. Conclusion: Our education program contributed to improvements in psychological distress, self-management skills, and coping and was appreciated by its attendees.

(c) 2016 S. Karger AG, Basel

\section{Introduction}

Inflammatory bowel disease (IBD) is a group of chronic diseases of the digestive tract with severe symptoms such as urgent diarrhea, abdominal pain, and cramping. Crohn's disease (CD) and ulcerative colitis (UC) are the most frequent types of IBD. Both are complex multifactorial diseases whose pathogenesis is not yet fully understood [1]. Psychological factors can influence the disease course and trigger new active disease episodes [2-4]. Furthermore, as

Anja Berding

Deutsche Morbus Crohn/Colitis ulcerosa Vereinigung - DCCV - e.V. Inselstrasse 1

DE-10179 Berlin (Germany)

E-Mail aberding@ dccv.de 
IBD is a lifelong and currently incurable condition, patients may experience a strong psychological burden, with fear of new acute episodes, complications or surgeries, concerns about losing their jobs $[5,6]$, or a reduced ability to work [7]. Additionally, many patients report an impact of their disease on numerous aspects of their daily activities and social life $[8,9]$. Rates of mental disorders such as anxiety and depression are increased [10].

Patient education programs are applied across various chronic diseases to help patients cope with the disease burden [e.g., 11, 12]. However, knowledge about the effectiveness of patient education in IBD is limited, and inconsistent methodology makes it difficult to draw conclusions. Still, there is a need for patient education in IBD, since patients often report having too little information about their disease and how to handle its sequelae $[13,14]$. Information of the patient is also an important part of the German and European treatment guidelines for IBD [15-18].

As yet, there are 2 studies evaluating the effect of patient education in IBD on disease-related worries and concerns. One study is a small prospective trial without a control group evaluating a psychoeducational program based on cognitive-behavioral principles [19]. A longterm reduction of worries and concerns was shown, but no effects were found on psychological distress, medication intake, disease activity, and active coping. The other study [20] yielded borderline significant effects on worries and concerns and other features of health-related quality of life (HRQoL) at 6 months compared to the waitlist control group (WL).

We created a manualized education program for IBD patients covering medical and psychological aspects. The aim of our study was to evaluate this new program in outpatients with long-lasting IBD. The primary outcome was disease-related worries and concerns at the 3-month follow-up (IBD Patient Concerns, IBDPC). Secondary outcomes included IBDPC subscales, fear of disease progression, coping with anxiety, skill and technique acquisition, positive and active engagement in life, as well as constructive attitudes and approaches. HRQoL, symptoms of depression and anxiety, perceived disease activity, knowledge, coping, and participants' satisfaction with the program were further secondary outcomes.

\section{Subjects and Methods}

\section{Study Design and Study Population}

This is a prospective, randomized study comparing 2 arms with predefined sample size. Group 1 consisted of patients receiving an intervention and group 2 patients served as waitlist controls with treatment as usual (no patient education). The study was conducted between 2011 and 2015 in outpatients in 8 IBD referral centers in Germany. Patients were recruited by the German Crohn's and Colitis Association (DCCV e.V., the German self-help organization for IBD) by sending study information to self-help groups, DCCV members, and interested patients all over Germany. Furthermore, gastroenterologists were asked to inform their IBD patients about the study. Advertisement in the DCCV member journal "Bauchredner," newsletters, and information on the DCCV website were also used.

Patients aged $\geq 18$ years with an established diagnosis of IBD were eligible. Exclusion criteria were insufficient language skills, severe vision or hearing impairments, and serious physical or psychological comorbidity (such as schizophrenia or major depression) which precluded patients from participating in the education program. They were assessed by the physicians and the psychologist who conducted the program. Attendance at an IBD patient education program up to 6 months prior to the study also led to exclusion. Out of 323 screened patients, 288 were eventually randomized to one of the 2 study groups. Allocation of the patients and study flow are depicted in Figure 1. To ensure allocation concealment, central block randomization (ratio 1:1) was used. For this, computer-generated numbers were conveyed by telephone or e-mail.

\section{The Education Program}

The intervention followed a manual (protocol) written by gastroenterologists and a psychologist. It considered the aims and principles of self-management patient education, the expertise of the project's advisory board (gastroenterologists, a nutritionist, a surgeon, and representatives of medical societies), recommendations of a center for patient education, and the results of a formative evaluation. Furthermore, a focus group of IBD patients provided input about needs and expectations concerning patient education. The final version of the program used a patient-centered approach with participants' active involvement in various tasks and discussions, which were designed to encourage them to share personal experiences and ask questions. The program consisted of 2 parts. The first one covered medical information, the second one provided coping and self-management skills. In addition, written material outlining the medical and self-management information was provided. The medical part conveyed information about the anatomy and function of the digestive tract, epidemiology and pathogenesis, clinical aspects, diagnosis and therapy (with a special focus on pharmaceutical and surgical therapy), complications and extraintestinal manifestations, as well as nutrition and pregnancy. IBD physician specialists experienced in performing patient education conducted it. The second part on coping and self-management skills was hold by a psychologist. It began with a moderated exchange of experiences, in which for example those inexperienced could ask questions to those experienced about how to best cope with the disease. Then participants presented individual strategies for coping with pain and negative emotions. Using 2 worksheets, doing something good for yourself and stress prevention (including guided progressive muscle relaxation), were addressed afterwards. Lastly, 3 short patient vignettes were used to discuss when and how to talk confidently about suffering from IBD.

The educational program was provided within 1 weekend. It was provided to batches of about 15 participants, which means that 16 courses were organized ( 8 for each intervention condition). The first part lasted $8 \mathrm{~h}$, the second one $3.5 \mathrm{~h}$. For formative evaluation 


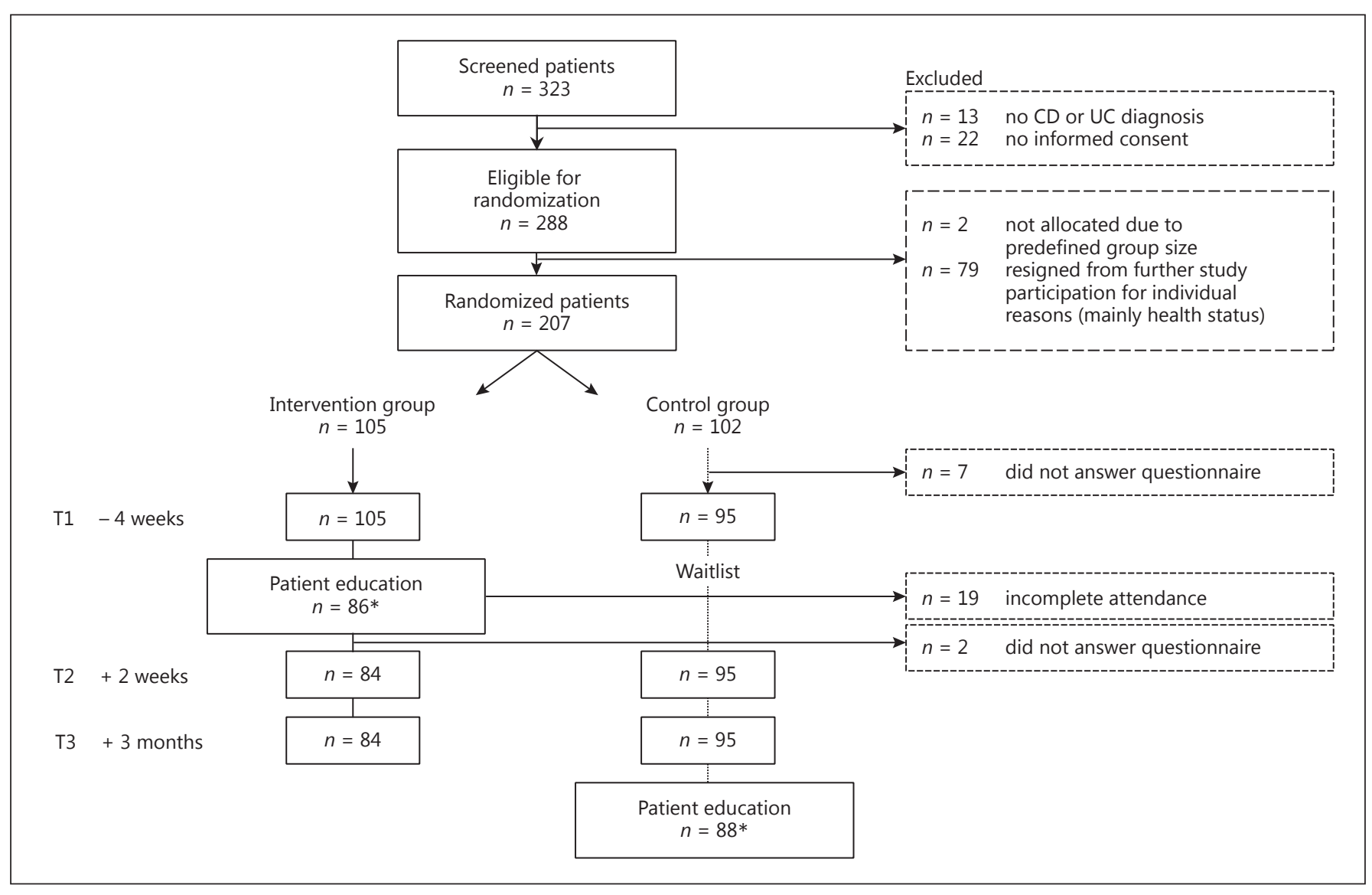

Fig. 1. Study design and excluded patients. CD, Crohn's disease; UC, ulcerative colitis. * Attended both sessions.

of acceptance of and satisfaction with the seminar, the education program was tested in 2 pilot sessions with a total of 21 subjects.

\section{Assessments}

Data were assessed at 3 time points: at baseline (T1) as well as 2 weeks (T2) and 3 months (T3) after the patient education seminar. After T3 the WL was also offered the intervention. At the beginning of the study (T1), demographic data and disease-related information were documented using a questionnaire. At T1, T2, and T3, assessments were performed as follows:

A modified validated German version (IBDPC) [21] of the Rating Form of IBD Patient Concerns questionnaire [5] was used to assess the most common disease-related worries and concerns of IBD patients. Each of its 25 items begins with "Because of my health condition, I am concerned with ..." and is rated on a 5-point Likert scale $(1=$ not at all to $5=$ very much). The IBDPC total score is calculated as the mean of 4 IBDPC subscales and 5 additional items. Impact of disease consists of 7 items (e.g., undergoing surgery, uncertain nature of the disease, side effects of medication). Stigmatization also includes 7 items (e.g., loss of bowel control, having an ostomy bag, being a burden on others). Sexuality (ability to perform sexually, restricted intimate life, loss of sexual drive) and Physical function (energy level, ability to achieve full potential, feelings about one's body) comprise 3 items each. Thereby, the to- tal score reflects worries and concerns about the somatic, psychosocial, and functional consequences of IBD.

Fear of progression was assessed using the Fear of Progression Questionnaire-Short Form (FoP-Q-SF) [22], a short version of the FoP-Q [23]. It consists of 12 items measuring fear of disease progression, suffering and losses due to disease, and resulting affective reactions on a 5 -point Likert scale ( $1=$ never to $5=$ very often $)$. The coping with anxiety scale of the FoP-Q comprises 9 items (e.g., talking about fears) and was additionally included to measure effective strategies when coping with fears of disease progression.

The Health Education Impact Questionnaire (heiQ) $[24,25]$ was applied to evaluate immediate (proximal) outcomes of patient education. Three of its 8 scales were used: (a) Positive and active engagement in life (5 items; e.g. "I try to make the most of my life"); (b) Skill and technique acquisition (4 items; e.g., "I have effective ways of preventing symptoms"); and (c) Constructive attitudes and approaches (5 items; e.g., "I try not to let my health problems stop me from enjoying life"). Each item is rated using a 4-point response scale ( 1 = strongly disagree to $4=$ strongly agree $)$.

Perceived disease activity was measured using the German Inflammatory Bowel Disease Activity Index (GIBDI) [26], which is a validated modification of common indices for CD (HarveyBradshaw Index, Crohn's Disease Activity Index) [27] and UC (Rachmilewitz Index, Clinical Activity Index) [28]. Both were 
adapted for postal assessment of disease activity within the last week. The GIBDI score (adapted range 0-18) indicates disease activity, which is categorized as inactive (score $0-3$ ), slightly active (score 4-7), moderate (score 8-11), or severe (score $\geq 12$ ). In line with the authors, patients with ostomies were excluded from all analyses that included the GIBDI.

HRQoL was assessed (not at T2) with the SF-12 questionnaire [29], a validated short version of the SF-36 [29], whose 12 items are divided into its 2 dimensions of physical and mental health-related quality of life. Higher scores indicate a better HRQoL.

The Patient Health Questionnaire-4 (PHQ-4) [30] was used as a screening instrument for depression and anxiety. In 4 items, symptoms occurring during the previous 2 weeks are rated on a 4 -point response scale $(1=$ not at all to $4=$ nearly every day). PHQ-4 scores $\geq 6$ are considered as cutoff points for a probable case of a depression or anxiety disorder (scores $\geq 3$ for the 2 subscales depression and anxiety, respectively).

Disease-related knowledge and handling of the disease were determined at all time points as well. Using 2 items, the participants estimated their level of knowledge about medical aspects and coping strategies, respectively. Two additional items asked for satisfaction with their current level of knowledge about both topics. Participants were also asked how well they were able to manage both the disease and disease-related negative emotions. All items were rated on a 5 -point Likert scale $(1=$ not [satisfied] at all to $5=$ much knowledge/very satisfied/very good).

To assess the use of coping strategies, participants were asked which of the coping strategies (e.g., talking to my family/friends, informing myself about IBD, spotting public toilet locations) from a list of 23 items they applied. This list (which is available from the first author upon request) was developed specifically for our study and was based on the contents of the program.

The participants' satisfaction with the program was evaluated using 5 items ("the seminar imparted new information to me"; "it will help me cope with my IBD"; "I am very satisfied with it"; "I would recommend it to others"; "I would take part in such a seminar again"). Answering options were graded on a 5-point Likert scale $(1=$ strongly disagree to $5=$ strongly agree $)$.

\section{Statistical Analysis}

The primary outcome was disease-related worries and concerns (IBDPC total score at T3). For sample size calculation, according to the literature [e.g., 31], a moderate difference between the intervention group (IG) and the WL was expected. A number of 154 patients was deemed necessary to detect a medium betweengroup difference at $\alpha=0.05,2$-sided, and $1-\beta=0.8$, accounting for a $20 \%$ dropout rate [32]. The effects of the patient education program were analyzed using analysis of covariance (ANCOVA) with the intervention condition being the independent variable. Partial $\eta^{2}\left(\eta_{\mathrm{p}}{ }^{2} ; 0.01 / 0.06 / 0.14\right.$ represent small/medium/large effects) [32] was used as an effect size measure. Each ANCOVA model was adjusted for the baseline measure of the respective outcome. Due to slight differences between the IG and the WL in baseline steroid intake, we repeated the analyses with perceived disease activity at $\mathrm{T} 1$ as an additional covariate. A 2-tailed $p<0.05$ was considered significant. For IBDPC subscales and other secondary outcomes, exploratory analyses without adjustment for multiple testing were performed. A sensitivity analysis checked for differences between the analytic sample and dropouts. IBM SPSS Statistics v. 22.0 (IBM Corp., Armonk, NY, USA) was used.

Patient Education in Inflammatory Bowel Disease

\section{Results}

Figure 1 depicts the allocation of the patients. We excluded participants who could not be allocated to the intervention condition due to (a) predefined group size ( $n=$ 2) and (b) resignation from further study participation for individual reasons (mainly health status; $n=79$ ), (c) who did not fill in the baseline questionnaire $(n=7)$, and (d) who attended only 1 of the 2 days $(n=19)$. The final analytic sample consisted of 181 participants (IG, $n=86$; WL, $n=95)$. A sensitivity analysis revealed no differences in characteristics between the analytic sample and the participants who dropped out during the course of the study.

\section{Characteristics of the Study Population}

The sample included 181 participants (31\% men, $48 \%$ in the IG) with a mean age (SD) of 39.9 (12.7) years. $45 \%$ of the participants were diagnosed with UC and 55\% with $\mathrm{CD}$. At baseline, the participants' disease was not active or had low activity, with average GIBDI scores (SD) of 2.9 (2.5) for UC and 3.4 (2.2) for CD patients. The IG and WL were balanced concerning their baseline characteristics (Table 1). Among the several parameters of disease history and disease burden, differences were only apparent in steroid intake $\left(\chi^{2}=10.68, p=0.001\right)$. Although significant, the effect was only small (Cramér's V $=0.246, p=$ $0.001)$.

\section{Effects of Patient Education on Psychosocial Outcomes and Disease Activity}

Our patient education program showed various significant beneficial effects after 2 weeks (T2) and 3 months (T3) when compared with the waitlist control condition (Table 2). The primary outcome of disease-related worries and concerns assessed using the IBDPC total scale was decreased by the intervention at both times of measurement (Fig. 2). All subscales of this instrument (Impact of disease, Stigmatization, Sexuality, and Physical function) showed similar improvements at T2 and T3. Regarding further secondary outcomes, fear of progression and coping with anxiety improved in the IG in comparison to the WL at T2 as well as T3. Significant differences in favor of the IG were also observed at both time points for dealing with the disease in a constructive way (measured by constructive attitudes and approaches as well as the acquisition of skills and techniques). Effects were stronger at T2 compared to T3, except for worries and concerns about the impact of disease and about stigmatization, coping with anxiety, as well as skill and technique acquisition.

Inflamm Intest Dis 2016;1:182-190 
Table 1. Characteristics of the intervention group and the waitlist control group

\begin{tabular}{|c|c|c|c|}
\hline & $\begin{array}{l}\text { Intervention group } \\
(n=86)\end{array}$ & $\begin{array}{l}\text { Waitlist control } \\
\text { group }(n=95)\end{array}$ & $p$ \\
\hline Diagnosis & & & 0.558 \\
\hline Crohn's disease & $57.0 \%$ & $52.6 \%$ & \\
\hline Ulcerative colitis & $43.0 \%$ & $47.4 \%$ & \\
\hline Proportion of men & $33.7 \%$ & $28.4 \%$ & 0.441 \\
\hline Age, years & $39.6(13.2)$ & $40.1(12.3)$ & 0.791 \\
\hline Currently working & $74.1 \%$ & $76.8 \%$ & 0.730 \\
\hline Education & & & 0.999 \\
\hline Less than junior ( $<10$ years; basic secondary school) & $8.2 \%$ & $8.4 \%$ & \\
\hline Junior (10 years; mid-level secondary school) & $38.8 \%$ & $38.9 \%$ & \\
\hline Higher education entrance qualification ( $12-13$ years) & $52.9 \%$ & $52.6 \%$ & \\
\hline \multicolumn{4}{|l|}{ Disease history and burden } \\
\hline Age at IBD diagnosis, years & $28.4(9.9)$ & $30.4(11.2)$ & 0.215 \\
\hline Disease duration, years & $10.9(10.8)$ & $9.6(8.9)$ & 0.403 \\
\hline Hospitalizations since diagnosis & $2.3(2.9)$ & $1.9(2.8)$ & 0.302 \\
\hline Patients with $0 / 1 />1$ rehabilitation(s) & $55.3 / 31.8 / 12.9 \%$ & $62.1 / 25.3 / 12.6 \%$ & 0.591 \\
\hline Patients with $0 / 1 />1$ operation(s) & $72.1 / 11.6 / 16.3 \%$ & $75.8 / 7.4 / 16.8 \%$ & 0.638 \\
\hline Flares during the last year & $2.1(2.2)$ & $2.5(3.0)$ & 0.372 \\
\hline Patients with medication intake in the last 3 months & $93.0 \%$ & $93.7 \%$ & 1.00 \\
\hline \multicolumn{4}{|l|}{ Current medication } \\
\hline 5-Aminosalicylic acid & $57.8 \%$ & $64.9 \%$ & 0.356 \\
\hline Steroids & $28.9 \%$ & $53.2 \%$ & 0.001 \\
\hline Immunosuppressants & $45.3 \%$ & $34.7 \%$ & 0.126 \\
\hline Biologicals & $10.5 \%$ & $12.6 \%$ & 0.817 \\
\hline \multicolumn{4}{|l|}{ Disease activity (GIBDI score) at T1 } \\
\hline Crohn's disease & $3.1(1.9)$ & $3.8(2.4)$ & 0.096 \\
\hline Ulcerative colitis & $2.9(3.0)$ & $4.1(3.2)$ & 0.093 \\
\hline
\end{tabular}

Values are percentage or mean (SD). GIBDI, German Inflammatory Bowel Disease Activity Index; IBD, inflammatory bowel disease; T1, before the intervention. A $p$ value $<0.05$ was considered significant.

We did not demonstrate any significant effects on positive and active engagement in life, symptoms of anxiety and depression, or perceived disease activity. In addition, neither physical nor mental health-related quality of life showed a significant intervention effect.

\section{Effects on Disease-Related Knowledge and Coping}

\section{with the Disease}

Moderate-to-large significant between-group effects in favor of the intervention condition could be observed at T2 and T3 for both level of and satisfaction with knowledge concerning medical aspects and coping strategies and success in coping with IBD as well as with IBD-related negative emotions (Table 2). Except for success in coping with IBD, the effects were stronger at T2 compared to T3. Furthermore, the IG used a larger number of coping strategies at T3; at T2 the difference was borderline significant.

Additional adjustment for perceived disease activity yielded basically similar results for all performed ANCOVA analyses.

\section{Subjective Evaluation of the Patient Education \\ Program}

After the patient education, participants were asked to evaluate their satisfaction with the program. The large majority rated the course very positive; $92 \%$ were very satisfied with it, $83 \%$ reported that the seminar provided support in coping with their IBD, for $84 \%$ it provided new knowledge, $84 \%$ would take part in such a seminar again, and $95 \%$ would recommend it to others.
Berding/Witte/Gottschald/Kaltz/Weiland/ Gerlich/Reusch/Kruis/Faller 
Table 2. Effects of patient education 2 weeks (T2) and 3 months (T3) after the seminar

\begin{tabular}{|c|c|c|c|c|c|c|c|c|c|c|}
\hline & \multicolumn{2}{|c|}{ Before intervention (T1) } & \multicolumn{4}{|c|}{2 weeks after intervention (T2) } & \multicolumn{4}{|c|}{3 months after intervention (T3) } \\
\hline & IG & WL & IG & WL & $\eta_{\mathrm{p}}^{2}$ & $p$ & IG & WL & $\eta_{p}^{2}$ & $p$ \\
\hline \multicolumn{11}{|l|}{ Worries and concerns (IBDPC) } \\
\hline Impact of disease & $2.98(0.80)$ & $2.95(0.84)$ & $2.54(0.70)$ & $2.77(0.81)$ & 0.056 & 0.002 & $2.46(0.77)$ & $2.81(0.86)$ & 0.102 & $<0.001$ \\
\hline Stigmatization & $2.40(0.94)$ & $2.40(0.98)$ & $2.16(0.92)$ & $2.41(0.96)$ & 0.045 & 0.005 & $2.13(0.88)$ & $2.42(0.99)$ & 0.069 & $<0.001$ \\
\hline Sexuality & $2.34(1.08)$ & $2.55(1.22)$ & $2.01(1.07)$ & $2.56(1.28)$ & 0.051 & 0.003 & $2.05(1.03)$ & $2.46(1.22)$ & 0.025 & 0.037 \\
\hline Physical function & $3.25(0.87)$ & $3.18(1.01)$ & $2.76(0.88)$ & $3.04(0.96)$ & 0.055 & 0.002 & $2.80(0.98)$ & $2.99(0.97)$ & 0.023 & 0.045 \\
\hline Total score & $2.61(0.74)$ & $2.63(0.82)$ & $2.26(0.70)$ & $2.57(0.83)$ & 0.088 & $<0.001$ & $2.25(0.71)$ & $2.55(0.85)$ & 0.080 & $<0.001$ \\
\hline Fear of progression (FoP-Q-SF) & $2.94(0.66)$ & $2.78(0.77)$ & $2.64(0.67)$ & $2.80(0.74)$ & 0.102 & $<0.001$ & $2.63(0.68)$ & $2.70(0.74)$ & 0.063 & 0.001 \\
\hline Coping with anxiety (FoP-Q) & $3.62(0.57)$ & $3.35(0.65)$ & $3.68(0.53)$ & $3.30(0.59)$ & 0.059 & 0.001 & $3.70(0.57)$ & $3.29(0.66)$ & 0.061 & 0.001 \\
\hline Constructive attitudes (heiQ) & $3.25(0.53)$ & $3.17(0.51)$ & $3.38(0.50)$ & $3.12(0.55)$ & 0.073 & $<0.001$ & $3.34(0.48)$ & $3.10(0.59)$ & 0.060 & 0.001 \\
\hline Skill and technique acquisition (heiQ) & $2.80(0.51)$ & $2.62(0.63)$ & $3.06(0.48)$ & $2.66(0.54)$ & 0.131 & $<0.001$ & $3.08(0.41)$ & $2.67(0.53)$ & 0.141 & $<0.001$ \\
\hline Positive and active engagement (heiQ) & $3.09(0.54)$ & $2.99(0.57)$ & $3.19(0.54)$ & $3.04(0.56)$ & 0.009 & 0.20 & $3.16(0.49)$ & $2.98(0.59)$ & 0.016 & 0.10 \\
\hline Disease activity (GIBDI) & $2.84(2.12)$ & $3.56(2.50)$ & $2.89(2.36)$ & $3.64(2.28)$ & 0.001 & 0.65 & $3.04(2.77)$ & $3.76(2.53)$ & 0.002 & 0.57 \\
\hline \multicolumn{11}{|l|}{ Anxiety and depression (PHQ-4) } \\
\hline Symptoms of anxiety & $1.64(1.38)$ & $1.73(1.44)$ & $1.48(1.38)$ & $1.65(1.38)$ & 0.002 & 0.56 & $1.46(1.47)$ & $1.57(1.47)$ & 0.001 & 0.75 \\
\hline Symptoms of depression & $1.71(1.49)$ & $1.82(1.49)$ & $1.36(1.21)$ & $1.72(1.43)$ & 0.015 & 0.11 & $1.48(1.40)$ & $1.65(1.45)$ & 0.001 & 0.63 \\
\hline \multicolumn{11}{|l|}{ HRQOL (SF-12) } \\
\hline Physical HRQoL & $46.58(9.20)$ & $45.99(8.79)$ & - & - & - & - & $47.62(9.08)$ & $46.60(9.16)$ & 0.002 & 0.54 \\
\hline Mental HRQoL & $44.31(11.76)$ & $42.74(10.37)$ & - & - & - & - & $46.41(11.00)$ & $42.70(10.89)$ & 0.011 & 0.18 \\
\hline \multicolumn{11}{|l|}{ Level of knowledge } \\
\hline Medical aspects & $3.35(0.72)$ & $3.42(0.74)$ & $4.23(0.48)$ & $3.44(0.65)$ & 0.462 & $<0.001$ & $4.05(0.41)$ & $3.42(0.71)$ & 0.311 & $<0.001$ \\
\hline Psychological aspects & $2.84(0.97)$ & $2.85(0.88)$ & $3.81(0.72)$ & $2.99(0.70)$ & 0.307 & $<0.001$ & $3.65(0.67)$ & $2.98(0.74)$ & 0.239 & $<0.001$ \\
\hline \multicolumn{11}{|l|}{ Satisfaction with level of knowledge } \\
\hline Medical aspects & $3.13(0.93)$ & $2.97(0.99)$ & $4.12(0.52)$ & $2.99(0.90)$ & 0.416 & $<0.001$ & $4.04(0.50)$ & $3.13(0.88)$ & 0.303 & $<0.001$ \\
\hline Psychological aspects & $2.59(1.07)$ & $2.54(1.03)$ & $3.80(0.71)$ & $2.73(0.87)$ & 0.350 & $<0.001$ & $3.85(0.70)$ & $3.02(0.84)$ & 0.253 & $<0.001$ \\
\hline \multicolumn{11}{|l|}{ Coping } \\
\hline With IBD & $3.70(0.69)$ & $3.51(0.77)$ & $4.08(0.55)$ & $3.59(0.75)$ & 0.113 & $<0.001$ & $4.06(0.61)$ & $3.51(0.73)$ & 0.148 & $<0.001$ \\
\hline With negative emotions & $3.16(0.97)$ & $3.00(0.84)$ & $3.58(0.78)$ & $3.19(0.78)$ & 0.057 & 0.001 & $3.54(0.81)$ & $3.18(0.90)$ & 0.040 & 0.008 \\
\hline Number of strategies & $8.69(3.35)$ & $8.06(3.37)$ & $9.45(3.50)$ & $8.27(3.54)$ & 0.021 & 0.05 & $9.39(3.58)$ & $8.03(3.32)$ & 0.036 & 0.011 \\
\hline
\end{tabular}

Values are mean (unadjusted) (SD). GIBDI, German Inflammatory Bowel Disease Activity Index; heiQ, Health Education Impact Questionnaire; HRQoL, health-related quality of life; IBD, inflammatory bowel disease; IBDPC, IBD Patient Concerns; IG, intervention group; PHQ-4, Patient Health Questionnaire-4; WL, waitlist control group; $\eta_{\mathrm{p}}{ }^{2}$, partial $\eta^{2}$, with $p$ values for between-group differences adjusting for baseline scores (analysis of covariance). A $p$ value $<0.05$ was considered significant.

\section{Discussion}

The patient education program developed and tested in this study proved to be effective. Comparison of our results with those of other recent studies, however, is difficult as there are many different definitions of patient education and a variety of approaches. One reason for this heterogeneity may be that IBD patients experience diverse problems. As a result, education programs focus on various aspects of IBD, making them to some extent noncomparable.

We could demonstrate a reduction in disease-related worries and concerns in patients who attended our course. Improvements were found both as early as after 2 weeks and after 3 months on the IBDPC total scale as well as all subscales, which indicates that the program improved a broad array of worries measured. Thus, effects of the intervention were observed also on those subscales that included the highest rated concerns, such as ability to achieve one's full potential, pain or suffering, energy level, side effects of medication, and the uncertain nature of the disease, indicating that the effects were relevant to participants. Similarly, Mussell et al. [19] reported that

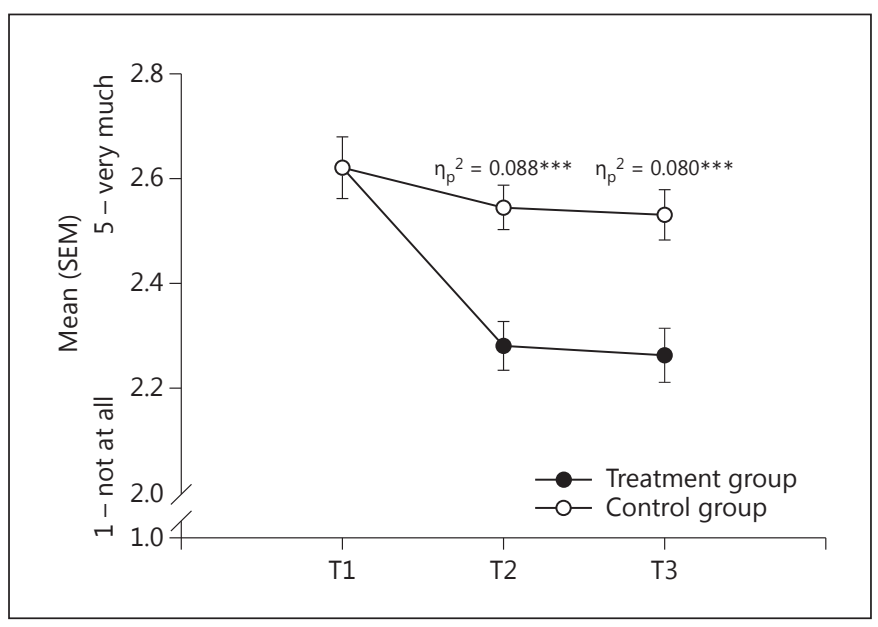

Fig. 2. Worries and concerns caused by inflammatory bowel disease (Inflammatory Bowel Disease Patient Concerns) before (T1) as well as 2 weeks (T2) and 3 months (T3) after intervention in the treatment and control group. Means are adjusted for baseline scores. SEM, standard error of the mean; $\eta_{\mathrm{p}}{ }^{2}$, partial $\eta^{2}$. ${ }^{* * *} p<$ 0.001 . 
the psychoeducational program they used led to a longterm reduction in worries and concerns. However, they did not use a control group, and the sample size was small. The only other study on disease-related worries and concerns applied a multiprofessional education program for IBD patients with short disease duration ( $<2$ years) [20]. The authors found borderline significant amelioration of worries and concerns and other aspects of HRQoL at 6 months. An initial significant reduction in worries and concerns in the IG 1 month after attending the program was not convincing, as there were no corresponding data on the control group, a major shortcoming of their study.

Our patient education seminar also reduced fear of progression and improved coping with anxiety. To the best of our knowledge, there are no other studies investigating these 2 outcome parameters in IBD. Additionally, the program enhanced coping with IBD and related negative emotions and increased the number of coping strategies employed. Thus, our study confirmed the finding of Kennedy et al. [31], who reported improvements in coping with IBD as well. In contrast, a psychoeducational program did not show any effects on active coping, while there was improvement in depressive coping in women [19]. Constructive attitudes and approaches as well as skill and technique acquisition, both measured by the heiQ, were also improved by our intervention. As our study was the first to apply the heiQ in the IBD context, a comparison with other studies is not possible. We also demonstrated a significant improvement in the perceived level of disease-related knowledge and satisfaction with it. This is in line with findings of other studies on IBD patient education, except for one that did not yield effects on knowledge [31,33-35]. The attendees of our seminar also highly appreciated the program.

Effects on perceived disease activity, positive and active engagement in life, HRQoL, or symptoms of anxiety and depression could not be shown. Since at baseline the average perceived disease activity was very low and both HRQoL scales were in the average range, improvements in these variables might be difficult to obtain due to ceiling effects. It seems worthwhile to investigate the effect of our program in IBD patients who are more severely affected. Our findings are in agreement with those of other studies that also showed no amelioration of HRQoL or depression and anxiety [20, 31, 34-41]. Most of them had very small samples, which might have made the detection of differences difficult [20,34, 35, 37-41]. Furthermore, some studies analyzed only within-group effects [37-39]. The Cochrane review by Timmer et al. [42] concluded that the effect of educational interventions in IBD on quality of life is very small and not statistically significant. In addition, programs aiming to enhance self-management seem to be more effective than solely educational ones [43]; promising effects are reported in a recent review [44].

Reports on the effects of patient education on disease activity are conflicting. Whereas some authors provided evidence for long-term improvements of symptoms [45] and disease course $[36,46]$, our study did not find such beneficial effects, which is in line with previous findings $[19,35,38]$.

One limitation of our study is that we used a waitlist control group that did not control for attention and expectation. Furthermore, selection bias might have occurred selecting healthier subjects. In addition, since participation was voluntary, it is likely that participants were more health-conscious, motivated, and educated. As the education program of our self-help organization is focused on patients without current need for hospital admission as well as on voluntary participation, the study sample closely mirrored the population targeted for further application of the program and may therefore be considered representative. Besides, recruitment via a wide range of approaches allowed low-threshold study participation and further strengthens representativeness of the study. Furthermore, slight differences between both intervention conditions in baseline steroid intake occurred. However, from our point of view, they do not question the results, especially as the additional correction for baseline disease activity did not change the effects. Another limitation is that the participants' CD and UC diagnoses were based on self-report, which might limit their accuracy. In addition, we did not use clinical parameters measured by physicians to assess disease activity or IBD-specific knowledge tests (e.g., CCKNOW [47] or KQ [48]). The SF-12 questionnaire did not assess HRQoL specifically for IBD, although HRQoL measurement tools designed for IBD patients (e.g., IBDQ-D [49]) might be more sensitive. This may explain our null results for HRQoL. However, we used the IBD-specific IBDPC questionnaire, which also deals with aspects of mental HRQoL, and found significant results.

Our study has several strengths. To our knowledge, it is one of the few studies showing a positive effect of an IBD education program combining medical and psychological modules. Furthermore, the study was randomized, controlled, and performed in a large sample as compared to other intervention studies in this field. Also, the program was based on widely accepted patient education aims and principles and combined medical and psychological aspects of IBD. Patient education can be costly and 
time-consuming. The advantage of our program that provided participants with comprehensive knowledge of IBD is that it was carried out over a short period of 2 days in a group-based seminar, and thus is feasible for routine use in our patient organization. Other strong points are that our study was multicentric and multiprofessional, involving gastroenterologists and a psychologist. Additionally, the program was developed in close collaboration with IBD patients so that it could be tailored to their needs, which enabled optimization of treatment effects.

In conclusion, the present study shows our patient education seminar to have several beneficial effects, especially on disease-related worries and concerns, fear of progression and coping with anxiety, perceived level of knowledge and satisfaction with it, coping with IBD and related negative emotions, the number of applied coping strategies, constructive attitudes and approaches, as well as skill and technique acquisition. The seminar was highly appreciated by the participants. We did not demonstrate any effects on perceived disease activity, HRQoL, positive and active engagement in life, or symptoms of anxiety and depression. Nonetheless, in view of the numerous beneficial effects and many positive acknowledgments, the program was included in the current education portfolio of our patient organization.

\section{Acknowledgments}

The authors thank all participants, all gastroenterologists who conducted the education program, and the advisory board for their contribution to the study. This work was supported by the German
Federal Ministry of Education and Research, the German Pension Insurance, the National Associations of Statutory Health Insurers, and the Association of Private Health Insurers (funding number 01GX1001).

\section{Author Contributions}

A.B. designed and coordinated the study, developed and organized the education program, and conducted it in cooperation with the participating gastroenterologists, acquired, analyzed, and interpreted the data, and wrote the manuscript. C.W. initiated and designed the study and accompanied the research process. M.G. analyzed and interpreted the data and wrote the manuscript. B.K. initiated and accompanied the project. H.F., A.R., and R.W. accompanied the research process. H.F. and A.R. also designed the study. R.W. was responsible for the external randomization and C.G. for data entry. W.K. served as member of the study board, helped with the methods, and contributed to the manuscript. All authors critically revised the manuscript and authorized the final version.

\section{Statement of Ethics}

The study was approved by the ethics committee of the medical faculty of the University of Würzburg and complied with the principles of the Declaration of Helsinki. Written informed consent was obtained from all participants.

\section{Disclosure Statement}

The authors have no personal interests to declare.

\section{References}

1 Stange EF (ed): Entzündliche Darmerkrankungen. Klinik, Diagnostik und Therapie. Stuttgart, Schattauer, 2015.

2 Mittermaier C, Dejaco C, Waldhoer T, et al: Impact of depressive mood on relapse in patients with inflammatory bowel disease: a prospective 18-month follow-up study. Psychosom Med 2004;66:79-84

3 Mardini HE, Kip KE, Wilson JW: Crohn's disease: a two-year prospective study of the association between psychological distress and disease activity. Dig Dis Sci 2004;49:492-497.

4 Maunder RG, Levenstein S: The role of stress in the development and clinical course of inflammatory bowel disease: epidemiological evidence. Curr Mol Med 2008;8:247-252.

5 Drossman DA, Leserman J, Li ZM, Mitchell CM, Zagami EA, Patrick DL: The Rating Form of IBD Patient Concerns: a new mea-

Patient Education in Inflammatory Bowel Disease sure of health status. Psychosom Med 1991; 53:701-712.

6 Mussell M, Böcker U, Nagel N, Singer MV: Predictors of disease-related concerns and other aspects of health-related quality of life in outpatients with inflammatory bowel disease. Eur J Gastroenterol Hepatol 2004;16: 1273-1280.

7 Bernklev T, Jahnsen J, Henriksen M, et al: Relationship between sick leave, unemployment, disability, and health-related quality of life in patients with inflammatory bowel disease. Inflamm Bowel Dis 2006;12:402412 .

8 Hardt J, Muche-Borowski C, Conrad S, Balzer $\mathrm{K}$, Bokemeyer B, Raspe H: Chronisch entzündliche Darmerkrankungen als multifokale Erkrankungen: körperliche und psychosoziale Probleme von Patienten mit CED.
Ergebnisse eines Fragebogen-Surveys. Z Gastroenterol 2010;48:381-391.

9 Hüppe A, Langbrandtner J, Raspe H: Komplexe psychosoziale Problemlagen bei Morbus Crohn und Colitis ulcerosa - fragebogengestütztes Assessment als erster Schritt zur Aktivierung von Patientinnen und Patienten. Z Gastroenterol 2013;51:257-270.

10 Mikocka-Walus A, Knowles SR, Keefer L, Graff L: Controversies revisited: a systematic review of depression and anxiety with inflammatory bowel diseases. Inflamm Bowel Dis 2016;22:752-762.

11 Warsi A, Wang PS, LaValley MP, Avorn J, Solomon DH: Self-management education programs in chronic disease: a systematic review and methodological critique of the literature. Arch Intern Med 2004;164:16411649. 
12 De Ridder D, Schreurs K: Developing interventions for chronically ill patients. Clin Psychol Rev 2001;21:205-240.

13 Baars JE, Siegel CA, van't Spijker A, Markus T, Kuipers EJ, van der Woude CJ: Inflammatory bowel disease-patients are insufficiently educated about the basic characteristics of their disease and the associated risk of colorectal cancer. Dig Liver Dis 2010;42:777784.

14 Conrad S, Hüppe A, Raspe H: Zu welchen Themen wünschen Patientinnen und Patienten mit Morbus Crohn oder Colitis ulcerosa mehr Informationen und welche eigene Rolle bevorzugen sie bei medizinischen Behandlungsentscheidungen? Ergebnisse einer Betroffenenbefragung in Deutschland. Z Gastroenterol 2012;50:364-372.

15 van Assche G, Dignass A, Reinisch W, et al: The second European evidence-based consensus on the diagnosis and management of Crohn's disease: special situations. J Crohns Colitis 2010;4:63-101.

16 van Assche G, Dignass A, Bokemeyer B, et al: Second European evidence-based consensus on the diagnosis and management of ulcerative colitis part 3: special situations. J Crohns Colitis 2013;7:1-33.

17 Dignass A, Preiß JC, Aust DE, et al: Aktualisierte Leitlinie zur Diagnostik und Therapie der Colitis ulcerosa 2011 - Ergebnisse einer evidenzbasierten Konsensuskonferenz. Z Gastroenterol 2011;49:1276-1341.

18 Preiß JC, Bokemeyer B, Buhr HJ, et al: Aktualisierte S3-Leitlinie "Diagnostik und Therapie des M. Crohn” 2014. Z Gastroenterol 2014;52:1431-1484.

19 Mussell M, Böcker U, Nagel N, Olbrich R, Singer MV: Reducing psychological distress in patients with inflammatory bowel disease by cognitive-behavioural treatment: exploratory study of effectiveness. Scand J Gastroenterol 2003;38:755-762.

20 Jäghult S, Larson J, Wredling R, Kapraali M: A multiprofessional education programme for patients with inflammatory bowel disease: a randomized controlled trial. Scand J Gastroenterol 2007;42:1452-1459.

21 Krebs H, Kachel F, Faller H: Der Fragebogen zur Erfassung der Sorgen von Patienten mit chronisch-entzündlichen Darmerkrankungen (IBD Patient Concerns): Ergebnisse zur Reliabilität und Validität einer deutschen Version. Prax Klin Verhaltensmed Rehab 1998;41:50-55.

22 Mehnert A, Herschbach P, Berg P, Henrich G, Koch U: Progredienzangst bei Brustkrebspatientinnen - Validierung der Kurzform des Progredienzangstfragebogens PA-F-KF. Z Psychosom Med Psychother 2006;52:274288.
23 Herschbach P, Berg P, Dankert A, et al: Fear of progression in chronic diseases: psychometric properties of the Fear of Progression Questionnaire. J Psychosom Res 2005;58: 505-511.

24 Osborne RH, Elsworth GR, Whitfield K: The Health Education Impact Questionnaire (heiQ): an outcomes and evaluation measure for patient education and self-management interventions for people with chronic conditions. Patient Educ Couns 2007;66:192-201.

25 Schuler M, Musekamp G, Faller H, et al: Assessment of proximal outcomes of self-management programs: translation and psychometric evaluation of a German version of the Health Education Impact Questionnaire (heiQ ${ }^{\mathrm{TM}}$ ). Qual Life Res 2013;22:1391-1403.

26 Janke KH, Raible A, Bauer M, et al: Questions on life satisfaction (FLZM) in inflammatory bowel disease. Int J Colorectal Dis 2004;19: 343-353.

27 Best WR, Becktel JM, Singleton JW, Kern F: Development of a Crohn's disease activity index. National Cooperative Crohn's Disease Study. Gastroenterology 1976;70:439-444.

28 Rachmilewitz D: Coated mesalazine (5-aminosalicylic acid) versus sulphasalazine in the treatment of active ulcerative colitis: a randomised trial. BMJ 1989;298:82-86.

29 Bullinger M, Kirchberger I: SF-36 Fragebogen zum Gesundheitszustand. Göttingen, Hogrefe, 1998.

30 Löwe B, Wahl I, Rose M, et al: A 4-item measure of depression and anxiety: validation and standardization of the Patient Health Questionnaire-4 (PHQ-4) in the general population. J Affect Disord 2010;122:86-95.

31 Kennedy AP, Nelson E, Reeves D, et al: A randomised controlled trial to assess the effectiveness and cost of a patient orientated self management approach to chronic inflammatory bowel disease. Gut 2004;53:1639-1645.

32 Cohen J: Statistical Power Analysis for the Behavioral Sciences. Hillsdale, NJ, Erlbaum, 1988.

33 Schreiber S, Haemling J, Wedel S, Nikolaus SN, Buhr HJ, Raedler A: Efficacy of patient education in chronic inflammatory bowel disease in a prospective controlled multicenter trial. Gastroenterology 1999;116:A3535.

34 Waters BM, Jensen L, Fedorak RN: Effects of formal education for patients with inflammatory bowel disease: a randomized controlled trial. Can J Gastroenterol 2005;19:235-244.

35 Bregenzer N, Lange A, Fürst A, Gross V, Schölmerich J, Andus T: Patient education in inflammatory bowel disease does not influence patients' knowledge and long-term psychosocial well-being. Z Gastroenterol 2005; 43:367-371.

36 Robinson A, Thompson DG, Wilkin D, Roberts C; the Northwest Gastrointestinal Research Group: Guided self-management and patient-directed follow-up of ulcerative colitis: a randomised trial. Lancet 2001;358:976981.
37 Larsson K, Sundberg Hjelm M, Karlbom U, Nordin K, Anderberg UM, Lööf L: A groupbased patient education programme for highanxiety patients with Crohn's disease or ulcerative colitis. Scand J Gastroenterol 2003; 38:763-769.

38 Smith GD, Watson R, McRorie D, et al: Impact of a nurse-led counselling service on quality of life in patients with inflammatory bowel disease. J Adv Nurs 2002;38:152-160.

39 Schwarz SP, Blanchard EB: Evaluation of a psychological treatment for inflammatory bowel disease. Behav Res Ther 1991;29:167177.

40 Díaz Sibaja MA, Comeche Moreno MI, Mas Hesse B: Protocolized cognitive-behavioral group therapy for inflammatory bowel disease. Rev Esp Enferm Dig 2007;99:593-598.

41 Oxelmark L, Magnusson A, Löfberg R, Hillerås $\mathrm{P}$ : Group-based intervention program in inflammatory bowel disease patients: effects on quality of life. Inflamm Bowel Dis 2007; 13 : 182-190.

42 Timmer A, Preiss JC, Motschall E, Rücker G, Jantschek G, Moser G: Psychological interventions for treatment of inflammatory bowel disease (review). Cochrane Libr 2011;5:1132.

43 Barlow C, Cooke D, Mulligan K, Beck E, Newman S: A critical review of self-management and educational interventions in inflammatory bowel disease. Gastroenterol Nurs 2010; 33:11-18.

44 Conley S, Redeker N: A systematic review of self-management interventions for inflammatory bowel disease. J Nurs Scholarsh 2016; 48:118-127.

45 Milne B, Joachim G, Niedhardt J: A stress management programme for inflammatory bowel disease patients. J Adv Nurs 1986;11: 561-567.

46 Keefer L, Kiebles JL, Martinovich Z, Cohen E, Van Denburg A, Barrett TA: Behavioral interventions may prolong remission in patients with inflammatory bowel disease. Behav Res Ther 2011;49:145-150.

47 Eaden JA, Abrams K, Mayberry JF: The Crohn's and Colitis Knowledge Score: a test for measuring patient knowledge in inflammatory bowel disease. Am J Gastroenterol 1999;94:3560-3566.

48 Jones SC, Gallacher B, Lobo AJ, Axon AT: A patient knowledge questionnaire in inflammatory bowel disease. J Clin Gastroenterol 1993; 17:21-24.

49 Janke KH, Klump B, Steder-Neukamm U, Hoffmann J, Häuser W: Validierung der Deutschen Version (Kompetenznetz "Chronisch entzündliche Darmerkrankungen”) des Inflammatory Bowel Disease Questionnaire IBDQ-D. Psychother Psychosom Med Psychol 2006;56:291-298. 